\title{
CONSUMO DE BAZUCO Y LA RUTA HACIA LA SITUACIÓN DE CALLE: CRÓNICAS Y ESCENARIOS DE LA VIVENCIA FAMILIAR
}

Recibido: noviembre del 2018

Aceptado: abril del 2019

César Moreno Baptista ${ }^{1}$, Gretel Espinosa Herrera ${ }^{2}$ Lorena Zapata Piedrahita ${ }^{3}$

\section{Resumen}

El objetivo de este trabajo es analizar los comportamientos y las relaciones interpersonales del grupo familiar en torno al consumo de bazuco en la experiencia de tres estudios de caso. Metodológicamentees un estudio de carácter etnográfico de corte descriptivo-cualitativo que utilizó entrevistas semiestructuradas, que privilegian la construcción de narrativas y experiencias de vida frente al bazuco. La investigación permite ver que la adicción al bazuco puede constituirse en un alto riesgo para la ruptura de las relaciones interpersonales a nivel laboral, familiar y comunitario y constituye un factor determinante de la habitabilidad en calle. El trabajo concluye que la adicción al bazuco se presenta como una experiencia dolorosa y difícil para todos los miembros del grupo familiar, es un proceso progresivo donde el consumidor experimenta deterioro físico y cognitivo que va teniendo efectos en la relación con su entorno social, al perder las habilidades de interacción.

Palabras clave: bazuco, consumo, drogas, familia, relaciones familiares.

\footnotetext{
${ }^{1}$ Doctor en Antropología. Profesor de la Universidad de Caldas

2 Doctora en Ciencias Sociales, Niñez y Juventud, CINDE. Profesora de la Universidad de Caldas.

${ }^{3}$ Magíster en Culturas y Droga. Catedrática de la Universidad de Caldas.
} 


\section{CRACK-COCAINE CONSUMPTION AND A ROUTE TO BEING HOMELESS: CHRONICLES AND SITUATIONS IN FAMILY EXPERIENCES}

César Moreno Baptista ${ }^{1}$, Gretel Espinosa Herrera ${ }^{2}$ Lorena Zapata Piedrahita ${ }^{3}$

\section{Abstract}

The objective of this research is to analyze the behavior and interpersonal relationships of the family group in terms of the consumption of crack-cocaine, from the experience of three case studies. The method is a ethnographic study with a descriptive-qualitative cut which used semi-structured interviews that gave priority to the construction of narratives and life experiences regarding crack-cocaine. Research allows us to se that addiction to crack-cocaine might become a high risk for the breaking of interpersonal relationships in a work, family and community level. Likewise, it represents a determinant factor for those who become homeless. The research concludes that addiction to crack-cocaine is a painful and difficult experience for all the members of the family; it is a process in which the addict experiences physical and cognitive deterioration, having later effects in their relationship with the social environment, since they lose interaction abilities. 


\section{O CONSUMO DE CRACK E O CAMINHO À SITUAÇÃO DE RUA : CRÔNICAS E CENÁRIOS DA VIVÊNCIA FAMILIAR}

César Moreno Baptista ${ }^{1}$, Gretel Espinosa Herrera ${ }^{2}$ Lorena Zapata Piedrahita ${ }^{3}$

\section{Resumo}

O objetivo deste trabalho é analisar os comportamentos e as relações interpessoais do grupo familiar sobre o consumo de crack (paco) na experiência de três estudos de caso. Metodologicamente, trata-se de um estudo de caráter etnográfico de corte descritivo-qualitativo, em que foram utilizadas entrevistas semiestruturadas, as quais privilegiaram a construção de narrativas e de experiências com a droga. A pesquisa permite observar que o vício em crack pode ser constituído em um alto risco para a ruptura das relações interpessoais no âmbito profissional, familiar e comunitário, e constitui um fator determinante da condição de morar na rua. Este trabalho conclui que o vício em crack é apresentado como uma experiência dolorosa e difícil para todos os membros do grupo familiar, é um processo progressivo em que o consumidor prova a deterioração física e cognitiva, que tem seus efeitos na relação com seu ambiente social, ao perder as habilidades de interação. 


\section{Introducción}

En la línea de investigación cultura y drogas de la Universidad de Caldas, se ha propuesto desde hace varios años (2010) adelantar algunos trabajos que tratan de analizar, desde los discursos de las personas, aquellos temas que establecen vínculos entre el consumo de drogas y el delito, o el uso de drogas y la habitabilidad en calle. Estos trabajos permiten evidenciar que las circunstancias que vinculan dichos fenómenos son complejos de comprender porque están relacionadas con múltiples factores que entran en juego: relacionados con el sujeto que usa drogas, al tipo de sustancia que se usa y el contexto sociocultural en el que se presenta el fenómeno. En términos de Schnitman, el fenómeno comprende factores psicológicos, químicos $\mathrm{y}$ ambientales.

En este orden de ideas, el debate sobre las drogas identifica al menos dos posturas frente al asunto: la prohibicionista y la no prohibicionista (1). La primera asume el tema de las drogas ilegales como marihuana, cocaína y heroína como un problema que amenaza la salud, el bienestar de los sujetos y de la sociedad en general. Esta posición relaciona el consumo de drogas con percepciones sobre la pérdida de valores en la sociedad, conductas desviadas, conductas delictivas y problemas de dependencia y adic- ción ${ }^{4}$. Dentro de este paradigma y de los múltiples discursos que circulan para controlar socialmente el uso de sustancias ilícitas, se presenta el dilema sobre la creencia que se ha desarrollado a partir de la satanización y la tabuización de las drogas 5 .

La otra posición (anti-prohibicionista) entiende el consumo de drogas como una práctica diferenciada por contextos socioculturales y ubica el consumo como un fenómeno que se encuentra dentro del régimen de las libertades individuales (2). En este sentido, los discursos de los grupos que exigen la despenalización de las drogas ilícitas argumentan que nos encontramos en un contexto mundial de defensa de los derechos ciudadanos y del desarrollo de las libertades públicas, lo cual sitúa el consumo de este tipo de sustancias como un derecho fundamental que atañe a la intimidad, la igualdad y el libre desarrollo de la personalidad ${ }^{6}$; sin embargo, más allá de asumir una posición frente a los polos prohibicionista o anti-prohibicionista, consideramos que el análisis etnográfico del hecho es necesario para comprender las causas, los procesos y los efectos en la sociedad.

En esta perspectiva es importante reconocer que, si bien el consumo de drogas puede examinarse como un tema asociado a la esfera de voluntad de los

\footnotetext{
${ }^{4}$ Sin embargo, como señala Ernesto Samper (2013) en su libro Drogas "La raíz del problema de la prohibición está hoy en que las drogas prohibidas no son malas porque hagan daño por sí mismas -que lo hacen-, sino que lo son por ser ilegales y su "maldad ilegal" tiene que ver cada vez menos con criterios científicos y más con decisiones políticas" (14).

5 "Los prohibicionistas piensan que mientras menos información sobre propiedades y efectos de las drogas tengan los potenciales consumidores, más alejados estarán del deseo de consumirlas" (14).

${ }^{6}$ Sentencia de la Cohorte Constitucional C-221-1994
} 
usuarios, es necesario pensar de manera diferencial el mundo de las drogas, para evitar las generalizaciones y la creación de mitos falsos que terminen poniendo en mayor riesgo a las poblaciones más vulnerables (como los niños y los adolescentes), lo anterior, a fin de lograr un trabajo más efectivo desde la política pública en la disminución del riesgo y el daño.

En este orden de ideas, este estudio se ha interesado en explorar el mundo de una de las sustancias que está produciendo los mayores y más indeseados efectos entre los individuos y en la sociedad, y que ha sido muy poco abordada en el análisis desde una perspectiva sociológica o antropológica; hacemos referencia al bazuco ${ }^{7}$. Al respecto, se ha evidenciado que la adicción a esta sustancia puede constituirse en un alto riesgo como generador de situaciones de ruptura entre las relaciones interpersonales y sociales de los sujetos, a nivel laboral, familiar y comunitario.

De acuerdo con información de prensa (El Espectador del 24 de agosto del 2009) (5), "en Colombia hay ocho millones de indigentes", siendo este uno de los grandes retos de la atención hospitalaria ${ }^{8}$. Al respecto el periódico señala:
- La sustancia que más se consume entre los habitantes de calle es el bazuco. La mayoría de los habitantes de calle son policonsumidores, pero la sustancia más problemática en el $80 \%$ de los pacientes es el bazuco.

- $\quad$ El $75 \%$ de quien consume bazuco se vuelve cada vez más adicto.

- La adicción se presenta por las características de la sustancia: cuanto más rápido actúa la sustancia en el organismo y más rápido se elimina, más necesidad tiene la persona de consumirla.

- La población de 25 a 35 años de edad es la más propensa a ser consumidora crónica (5).

Así, es preocupante el alto porcentaje de personas con estilos de vida en la calle asociada al consumo de bazuco que han perdido totalmente el vínculo con su grupo familiar, un vínculo que se constituye en un ámbito significativo si se intentan comprender los elementos relacionados con la huida hacia la calle y la posterior ubicación y permanencia en ella. En este sentido, el informe del periódico El Tiempo (26 de diciembre del 2016) señala que existe un alto porcen-

\footnotetext{
7 "En el argot de los adictos, se le llama bazuko, baserolo, susuki, zuko, y es, como droga, una de las más tóxicas que se pueden ingerir. Es, en esencia, extracto crudo de las hojas de coca sin refinar. Su procesamiento es tan elemental que generalmente se produce a nivel doméstico: se macera la coca liberando la savia, se rocía con bicarbonato, se disuelve en gasolina y se filtra. A menudo se utilizan también ácido sulfúrico, cloroformo, éter y kerosene. El resultado es una base de coca, altamente venenosa y peligrosa por cuanto no se sabe a ciencia cierta qué sustancias la componen. Generalmente, además, se vende adulterada con harina de plátano, Cerelac, azúcar, harina de trigo, maicena u otros elementos. Otro procedimiento para llegar al bazuko -este sólo para los ricos- es el "patraseado", que consiste en partir de la cocaína pura y "echar para atrás" (hacer el proceso inverso), disolviéndola en agua y mezclándole amoníaco" (15).

${ }^{8}$ El bazuco, el gran azote de los habitantes de la calle (16.)
} 
taje de habitantes de calle que tienen familia, pero han perdido la conexión con ellas, situación generada en gran medida por los conflictos que se crean a partir de los diversos comportamientos que afectan la convivencia y las relaciones dentro del grupo familiar, asociados al uso de drogas en general y en particular al bazuco (16).

En este orden de ideas, los problemas de adicción generan perspectivas de vida que los miembros del grupo y las personas cercanas no desean enfrentar. Los adictos tienen cambios en la personalidad, con frecuencia padecen enfermedades crónicas y las personas de su entorno viven bajo la coacción de la violencia, la humillación, los tratamientos fracasados, el agotamiento, la desesperanza y los problemas económicos. Estas situaciones con frecuencia generan rechazo social, exclusión y autoexclusión, provocada por la mala imagen que en ocasiones las personas adictas tienen de sí mismos, entendiendo que todo lo que hacen, dicen o piensan, está mal. De esta manera, y como resultado del proceso adictivo, se deterioran las relaciones y la comunicación en el orden familiar, personal, laboral y comunitario.

Todo lo anterior plantea la necesidad de ampliar el conocimiento sobre el fenómeno que se presenta y comprender la variedad de elementos que subyacen a él. Así, el presente trabajo muestra cómo son los comportamientos y las interacciones del grupo familiar en torno al consumo de bazuco, para analizar las experiencias de tres estudios de caso.

El argumento que se quiere sustentar gira en torno a la idea de cómo la familia y los sujetos que la conforman tienden a mantener las relaciones internas del grupo dentro de un orden social establecido que garantiza la estabilidad y la reproducción del mismo ${ }^{9}$, al tener en cuenta que esas dinámicas pueden ser diferentes en cada grupo. Los conflictos familiares que se configuran en torno al consumo de bazuco y la recurrencia de comportamientos que traspasan los límites entre lo aceptado y lo no aceptado llevan a un desgaste en las relaciones interpersonales y afectan el ambiente familiar; lo que termina, con frecuencia, en un tránsito al estilo de vida en la calle.

\section{Material y métodos}

Como se señaló más arriba, el objetivo de este trabajo es analizar los comportamientos y las relaciones interpersonales del grupo familiar en torno al consumo de bazuco en la experiencia de tres estudios de caso. Para lo cual se hacen descripciones sobre relatos de vida de experiencias familiares que han contado con miembros con adicción al bazuco; se describen los recorridos de las personas en su adicción al bazuco hasta adoptar el modo de vida en la calle y se contrastan comparativamente los casos estudiados, a fin de evidenciar elementos comunes entre ellos.

\footnotetext{
${ }^{9}$ Mucho antes de que los sujetos se vean afectados por estructuras socioculturales de oportunidad, acceso y condiciones socioeconómicas, son influenciados por sus familias. En el discurso sociológico Bourdieu plantea la familia como un mandato social: "el mandato de vivir en familia es el mandato de construcción del orden social" (3).
} 
Los antecedentes de trabajo de campo de la presente investigación se remontan al año $2013^{10}$, en el que tuvimos la oportunidad de interactuar con un grupo aproximado de 80 personas (hombres) en un hogar de paso para habitantes de calle en la ciudad de Manizales ${ }^{11}$. Durante este tiempo se pudo conocer sobre sus trayectorias familiares, su experiencia con las drogas, su experiencia en la vida de la calle y sobre la experiencia institucional en el hogar de paso. De allí se pudo evidenciar que existen múltiples factores determinantes para que una persona adopte un estilo de vida en la calle, dentro de los cuales, las condiciones socioeconómicas y familiares influyen para que las personas desde temprana edad se asocien al mundo de las drogas y a la vida en la calle. Entre esos múltiples factores aparecen también de manera importante los momentos de crisis personales o familiares, así como el mundo de los pares, la curiosidad y los diferentes momentos del ciclo vital de las personas, entre otros; sin embargo, en dicha investigación se evidenció también cierta tipología entre las diferentes personas que optan por vivir en la calle. Algunos adoptan este estilo de vida de manera voluntaria, asumiéndolo como una opción de búsqueda de "libertad", de conocer y recorrer el mundo ${ }^{12}$, otros terminan en la calle por situaciones familiares asociadas a tensiones conyuga- les, procesos de violencia, dificultades económicas, entre otros elementos. Así, se identificó otro grupo: aquellos sujetos con una formación académica profesional o universitaria que constituían una minoría dentro del universo observado, pero que de igual forma habían terminado adoptando un estilo de vida en la calle, en situaciones y condiciones similares a los otros.

La constante en la mayoría de los sujetos de estudio fue el policonsumo de sustancias psicoactivas (cigarrillo, alcohol, marihuana, cocaína, pepas, ácidos, bazuco, pegante). La mayoría de ellos, manifestó en algún momento de su vida ser consumidor de bazuco y expresaron cierto "miedo" / "respeto", "gusto" / "rechazo", "placer", "hedonismo" al consumir la sustancia. Hallamos que esta práctica se describe como una experiencia angelical pero también "demoníaca”. En la mayoría de los casos los testimonios señalaron que la experiencia con el bazuco fue determinante para adoptar un modo de vida en la calle.

Dicho lo anterior, se planteó hacer una indagación en torno a aquellas personas que al tener una formación académica superior o profesional terminaron viviendo en la calle. En esta perspectiva, se buscó conocer la experiencia familiar durante el recorrido de la perso-

\footnotetext{
${ }^{10}$ Los primeros resultados del abordaje de esta problemática se evidencian en el artículo "Etnografía de prácticas delictivas y consumo de sustancias psicoactivas ilícitas entre jóvenes infractores de la ciudad de Manizales” (17).

${ }^{11}$ Una segunda etapa de la investigación se realizó con el apoyo de la Vicerrectoría de Investigaciones y Posgrados de la Universidad de Caldas entre 2013 y 2015, y sus resultados se publicaron en 2017 en el artículo titulado: "Entre el hogar y el asfalto: relatos y experiencias de vida en el consumo de SPA en habitantes de la calle de la ciudad de Manizales"7.

${ }^{12}$ De esta forma se encontraron personas que viajaban de ciudad en ciudad o de país en país, sin necesariamente un rumbo fijo, más que el de llevar una vida nómada.
} 
na que cae en la dependencia al bazuco y la forma en cómo se desenvuelven las relaciones familiares hasta el momento en que se rompe la convivencia en el hogar.

La investigación se desarrolló en perspectiva de un estudio descriptivo-cualitativo que utilizó entrevistas semi-estructuradas. $\mathrm{Al}$ aproximarnos a los familiares de estos sujetos se pudieron identificar temáticas centrales para elaborar el guión de las entrevistas, privilegiando la construcción de narrativas y las experiencias de vida frente al bazuco como instrumento etnográfico que recurre a la expresión en conjunto de las experiencias vividas a lo largo del proceso. El relato permitió el registro de una conversación, frente a situaciones específicas, que tuvo como punto de partida la interrogante: ¿qué tipo de conexidad se presenta entre el consumo de bazuco y el fenómeno de habitabilidad en calle en el contexto del ámbito familiar? Con lo anterior se trataron de analizar los patrones comunes desde diferentes experiencias. Con este propósito hemos tomado tres casos de familias que viven las experiencias de tener un miembro del grupo que ha decidido asumir la vida en la calle.

\section{Elementos conceptuales}

Desde el discurso sociológico de Bourdieu, la familia “...es concebida como un agente activo, dotado de voluntad, capaz de pensamiento, de sentimiento y de acción, y basado en un conjunto de presuposiciones cognitivas y de prescrip-

314 ciones normativas referidas a la manera correcta de vivir las relaciones domésti- cas" (1994). Es entendida como un universo en el que están suspendidas las leyes corrientes del mundo económico, es el lugar de la confianza por oposición al mercado, es la palabra que “...designa de hecho el rechazo del espíritu de cálculo; el lugar donde se deja en suspenso el interés en el sentido estricto del término, es decir, la búsqueda de la equivalencia en los intercambios" (3).

La familia se define también desde una perspectiva sistémica como: "un conjunto organizado e interdependiente de personas en constante interacción, que se regula por unas reglas y por funciones dinámicas que existen entre sí y con el exterior" (4). Desde esta perspectiva, el análisis de la familia se orienta hacia el conocimiento de un grupo con identidad propi y como escenario de un entramado complejo de relaciones.

Siguiendo el planteamiento de estos últimos autores, algunas características principales del sistema familiar es el considerarse como: conjunto, estructura, personas e interacción, atribuible al tipo de sistemas abiertos. En tanto conjunto, la familia se considera una totalidad (una Gestalt), "esta totalidad se constituye mediante un sistema de valores y creencias compartidos, por las experiencias vividas a lo largo de la vida y por los rituales y costumbres que se transmiten generacionalmente" (4). Como todo sistema, la familia lleva consigo una estructura y una organización en la vida cotidiana, lo que implica la existencia de jerarquías y reglas de interacción entre los miembros. Estas reglas de interacción regulan la relación entre familiares y definen quién 
pertenece y quién queda excluido del grupo familiar (4).

Finalmente, en la perspectiva de los mismos autores, la familia además de ser un conjunto estructurado se caracteriza por las personas y las interacciones entre ellas. En este sentido y en una orientación constructivista, los miembros de la familia se ven como actores capaces de producir o generar cambios con impacto en el resto del sistema. Las interacciones implican a todos, adultos y niños, enfermos y sanos, dominantes y dominados, porque todos contribuyen a configurar el sistema.

Ahora bien, el fenómeno de la habitabilidad en calle nos proyecta sobre los patrones de comportamiento de la vida cotidiana adoptados que se plantean como límite, pero también como condición de su existencia o su forma de vida particular, podríamos decir: sobre su "estilo de vida", siendo "el cuerpo el lugar de confluencia para la formalización de los estilos de vida de los individuos y de los grupos sociales" (6). En este sentido, la habitabilidad en calle se constituye como un "modo de vida" que adoptan los individuos por diferentes razones, en el caso particular de este estudio se encuentra asociado a la dependencia al bazuco ${ }^{13}$. En el artículo "Entre el hogar y el asfalto: relatos y experiencia de vida de habitantes en condición de calle" (7), los autores señalan diferentes factores que llevan a que los individuos entren al mundo de la habitabilidad en calle, de acuerdo con las condiciones sociales y la pluralidad de los procesos de socialización (7).

Así, el estilo de vida en la calle con dependencia al bazuco tiene unos efectos sobre el sistema familiar. En este contexto, cuando las relaciones domésticas o familiares se ven afectadas por el comportamiento "desviado" de uno de sus miembros, se comienzan a generar situaciones de malestar, tensión y conflictos al interior del grupo. Frente al tránsito entre el hogar y la habitabilidad en la calle8 se referencian algunos aspectos que favorecen la salida a este modo de vida en la calle: ausencia de comunicación, tensiones conyugales y fraternales, comportamientos por fuera de las pautas establecidas, situaciones de violencia, falta de afecto, rechazo, ejercicio inadecuado de la autoridad, abandono de responsabilidades, maltrato físico y verbal, entre otros elementos. De otro lado, es importante resaltar que "los sujetos consumidores de bazuco no todos lo hacen de una manera compulsiva; se identificaron dos manifestaciones sociopsicológicas del carácter: el consumidor experiencia y el consumidor compulsión, las cuales se caracterizan por tener de referencia el cuidado de sí" (9).

\section{Resultados}

\section{De la marihuana y otras drogas al consumo de bazuco}

En las trayectorias biográficas relatadas, Efraín, Oscar y Jhon son tres adultos con

\footnotetext{
${ }^{13}$ Los psicólogos distinguen entre el abuso de sustancias por el uso repetido de las mismas, que no implica adicción, 
nivel educativo superior. Uno de ellos residente en la ciudad de Bogotá y los otros dos en Manizales. Su formación universitaria estuvo relacionada con las áreas de las matemáticas, la física y la arquitectura, este nivel de formación permitió, en el caso de Efraín y John, ingresar en el escenario laboral con importantes responsabilidades en sus áreas de desempeño. Los tres casos aparecen inmersos en las dinámicas propias de un grupo familiar de clase media, en las que los individuos observados se desempeñan en el núcleo de los roles, como el caso de Efraín, en el de Oscar de padre y esposo, y en el caso de Jhon los roles de hijo y hermano, asumiendo compromisos económicos y afectivos con los miembros del grupo y con otros parientes.

En los tres casos observados hubo consumo de marihuana, frente a lo cual se evidencian diversas posiciones por parte de los miembros de la familia. En el caso de John, sus padres no están de acuerdo con que consuma sustancias prohibidas y la familia en general asume una posición de señalamiento y prohibición frente al consumo. Efraín y Oscar, también consumidores de marihuana, tenían un consumo abierto del cual sus esposas conocían, sin embargo, ello no representaba problemas en la convivencia familiar en tanto cumplían sus obligaciones laborales, económicas y familiares.

En los diferentes testimonios familiares se señala:
El consumo de marihuana de Jhon empieza a manifestarse en grado once (sexto grado de bachillerato), como uso ocasional y recreativo los fines de semana, notándose algunos estados de aletargamiento y sueño, en las reuniones de familia participaba pasivamente, se permitía diálogos cortos, sin interrumpir con la dinámica familiar, su rendimiento académico era bueno (comenta su hermana).

Efraín siempre fumó marihuana, sin embargo, su vida era normal, en la casa y en el trabajo era muy respetuoso. Nunca hubo quejas de que llegara borracho o bajo el efecto de sustancias psicoactivas al colegio (donde trabajaba), nunca tuvo problemas con estudiantes u otros profesores. El consumo de marihuana no fue un obstáculo para la normalidad de las relaciones con sus hijos y su pareja, no fue el mejor padre porque siempre fue alejado (dice Gloria, su sobrina), pero se ocupaba de lo básico en la casa.

Oscar siempre fumó cigarrillo, señala Nancy (su esposa), y de vez en cuando consumía marihuana, nunca lo vi que consumiera otra sustancia. A Oscar le gustaba la política, la bohemia, la poesía y trabajaba la metalistería (Técnica y arte de trabajar metales) con lo que obtenía algunos recursos, aunque ganaba poco y Nancy llevaba la mayor parte de la responsabilidad económica

Los tres casos transitaron del consumo de marihuana, alcohol y presuntamente otras sustancias como perico ${ }^{14} \mathrm{y}$ pe- 
gante (en el caso de Efraín), al consumo de bazuco. Los comportamientos atípicos en el ámbito familiar se hacen evidentes en el momento en que cada uno de ellos se implica con el uso del bazuco, particularmente en las etapas de dependencia a la sustancia. Progresivamente, en la medida en que se va desarrollando mayor dependencia, el comportamiento de las personas adictas se torna sobresaltado, y va fomentando paulatinamente el aumento del nivel de tensiones interpersonales en el ambiente familiar, extendiéndose luego al ámbito laboral.

A veces cuando regresaba del trabajo le notaba un comportamiento extraño, algo diferente, parecía como si hubiera bebido alcohol o muy agresivo, como perdido... Oscar era un hombre corpulento y apuesto, dice Nancy, pero después comencé a verlo que había cambiado en su aspecto físico, lo veía muy delgado. Pasó el tiempo y observaba el descuido de Oscar en sus obligaciones de trabajo, igualmente en su rol de esposo era una persona desentendida con los compromisos de pareja y de padre... empezó a incumplir los horarios de comida, llegaba sin apetito, pero en ocasiones sentía mucha hambre y devoraba todo lo que podía. En ese momento había pasado un tiempo que Oscar había salido de la Universidad por rendimiento académico.

...con el bazuco llegó el deterioro en la vida familiar y laboral, dice Rosa (la esposa de Efraín). Se acrecentaron los problemas porque Efraín incumplía con los compromisos económicos en el hogar. Comienza a llegar bajo los efectos del alcohol y otras drogas, con lo cual su temperamento se mostraba muy explosivo, soez y agresivo verbalmente, no físicamente, hasta el punto en que todos en la casa sentían miedo. Efraín regularmente se marchaba y no regresaba a la casa en varios días y cuando regresaba lo hacía en un estado deplorable. Rosa en un intento por controlar la situación, cambió las chapas de las puertas para no permitir el ingreso; pero un día, como la casa era de su propiedad, Efraín decide venderla... Esta situación fue muy impactante para todos, en especial para Rosa y los niños, verse en la calle, sin casa propia y sin saber de dónde sacar el dinero del arriendo de cada mes..., (recuerda uno de los familiares de Efraín).

Con la experiencia del uso del bazuco se comienzan a traspasar los límites de lo aceptado social y familiarmente, lo que incide en el quiebre de las relaciones y vínculos. Estas situaciones están determinadas por abandono de responsabilidades, descuido de la apariencia personal, comportamientos agresivos, indiferencia ante las situaciones familiares, abandono de los papeles conyugales, parentales y fraternales, conductas reiteradas de irritabilidad, entre otros. En términos fenomenológicos podría decirse que el bazuco afecta comportamentalmente la capacidad de la comprensión objetiva del mundo cotidiano, altera las funciones vitales y genera un 
estado de pérdida de la voluntad, entre otros efectos ${ }^{15}$. En este sentido es importante resaltar que el consumo del bazuco no solo afecta el equilibrio químico y neuronal de nuestro cerebro, sino que además implica psicopatologías en la conducta, el pensamiento y las emociones, entre otros cambios que afectan las relaciones en la familia, su entorno laboral y afectivo, y la noción de los parámetros sociales y culturales establecidos (10).

En el caso de Jhon, que empieza a mostrar mayores estados de irritabilidad, el ambiente familiar se torna tenso. Las ausencias prolongadas en el hogar y la poca comunicación con la familia se vuelven progresivamente más frecuentes. Su madre (Claudia) cuenta que no cumplía con las responsabilidades en el hogar, las peleas y las discusiones se volvieron costumbre

... mi angustia, desesperación y dolor se agudizaron, una vez recuerdo que se me llevó una alcancía que estaba ahorrando para los estudios de los otros hijos, ya desde ahí le cogí mucha desconfianza, ya no podía dejar nada de valor por fuera, él se llevaba cosas para vender y sostener el vicio...en la empresa donde trabajaba no tardó en empeorar su situación, después de recurrentes llegadas tarde y algunas sanciones se retiró de la empresa".

El deterioro de John se va evidenciando en la despreocupación por su presentación y aseo personal, el deterioro progresivo de su aspecto físico (se observa más flaco, pálido), el desorden en los hábitos alimenticios y el aislamiento (permanece tiempos prolongados en su habitación para evitar las interacciones y la comunicación con la familia).

En cierta ocasión se siente un olor extraño en la casa, un olor nauseabundo similar al caucho quemado. El padre baja a la habitación de Jhon y lo encuentra encendiendo una lata de cerveza como si fuera una pipa. Reacciona con violencia agrediéndolo físicamente para tratar de retirar el artefacto de su boca. Jhon se encuentra bajo los efectos del bazuco, asimila sin reaccionar los golpes y las palabras de reclamo del padre.

\footnotetext{
${ }^{15}$ Se hace referencia a un círculo vicioso de placer y displacer. Durante este momento el displacer aparece de manera muy rápida necesitando dosis más altas en búsqueda de esa primera sensación. El displacer lleva al adicto a "estar amurado" (estado alterado de conciencia, sensación de querer escapar, de encontrar bazuco). Es una manera compulsiva de consumir cada vez más droga. Su potencial adictivo prolonga las sensaciones de desasosiego, la habilidad emocional, depresión y aislamiento, que son los estados más comunes de sus efectos. Al bazuco se le atribuye esta dependencia emocional por ser un depresor del sistema nervioso central, que provoca inicialmente sensación de placer y luego delirio de persecución y de angustia llamados en su argot "el paniqueo y estar arañado". Son síntomas que llevan al adicto a un estado de alerta, a sentir miedos irracionales, múltiples sensaciones de excitación y de asumir riesgos y poderío de agresividad.

La manera más conocida de ingesta del bazuco es a través de la pipa; con cada bocanada de humo el consumidor retiene la respiración en su garganta para dejar que llegue al cerebro y se "arrunche" (prolongar su efecto por unos segundos más). La modalidad de consumo con la pipa, conocida como Suzuki o Suspiro del diablo, por su mayor prolongación durante el consumo, genera mayor dependencia que cuando la sustancia se fuma en un cigarrillo (maduro: cigarrillo de marihuana y bazuco), poco a poco la pipa se convierte en una extensión del cuerpo del adicto. La pipa artesanal se construye con materiales de fácil acceso: una mina de lapicero kilométrico, caucho, papel de aluminio, tubo pequeño de PVC; simbólicamente este instrumento es el medio que salva su vida. El adicto, sin poder entender el laberinto que protagoniza, una vez entra al juego se convierte en parte de un círculo vicioso caracterizado por un placer de duración ultrafugaz, aletargamiento y cansancio permanente.
} 
En lo sucesivo se hacen recurrentes los altercados en la casa y la violencia del padre hacia Jhon. Los hermanos menores, entre la decepción y la impotencia de ver al hermano mayor asumiendo una vida con amigos en la calle y despreocupado por la situación que vive la familia en relación con su consumo de drogas, manifiestan reiteradamente una actitud despectiva al verlo. Desde entonces, la vida de Jhon se va desmoronando por pedazos, su realidad carece de límites, abandona el trabajo y se evidencia una clara pérdida afectiva con los suyos.

\section{Distanciamiento de la casa y tránsito a la calle}

¿Cómo escala el conflicto hasta que se vuelve una ruptura?

La adopción de un estilo de vida en la calle se relaciona con un progresivo abandono del hogar. Esta salida puede ser gradual y puede estar acompañada por breves experiencias de intermitencia hasta llegar al hábito o costumbre de vida permanente en la calle. En este orden de ideas, esta situación se relaciona también con un progresivo rechazo por parte del grupo familiar debido a la imposibilidad de controlar los comportamientos de la persona adicta al bazuco. El robo en el hogar para mantener el consumo de la droga, las agresiones a otros miembros del grupo familiar, la irresponsabilidad por parte de la persona que consume con los roles asignados, entre otros comportamientos, son situaciones que se van haciendo rutinarias en el ambiente del hogar, lo que hace que los demás miembros vean resquebrajada la confianza, que empiecen a sentir resentimiento, dolor y comiencen a asumir posiciones de rechazo más firmes frente al adicto.

En la casa, [señala la mamá de Jhon] sin empleo, Jhon empieza a consumir de manera más seguida, consumía cuando no estábamos, cuando no lo veíamos, yo ya me sentía demasiado preocupada... no quería trabajar, solo consumir ... hasta que un día le dije: le doy plazo de dos meses para que se organice, y si no va a dejar esa droga, entonces usted verá que prefiere: sigue con su droga y se separa de aquí de la casa porque yo aquí no le voy admitir tanta sinvergüenzada porque yo ya estoy muy vieja, trabajando para tener un sinvergüenza aquí en la casa.

John termina yéndose de la casa, pidiendo posada en casa de algún amigo vecino. Así estuvo un tiempo cerca de la casa... se veía demacrado y perdido en la calle.

De otro lado, luego que Nancy se entera de la adicción de Oscar al bazuco, Nancy (su pareja) intenta darle un significado a la situación desde su perspectiva profesional como psicóloga y comprende que lo que Oscar vive es una patología. Así, comenzó a buscar ayuda profesional y el apoyo de su familia. Oscar comenzaba programas de tratamiento que Nancy conseguía, pero luego de un tiempo él recaía y los abandonaba. Poco a poco, la voluntad de Nancy se fue desmoronando y comenzó a distanciarse.

Estando en Bogotá, Nancy recibió el apoyo de una de sus hermanas que viajó al exterior y le cedió su apartamento con la condición de que Oscar no entrara. 
Eso fue determinante para que Nancy y su familia tomaran distancia y Oscar comenzó a buscar a su familia materna. Estuvo un tiempo en casa de su mamá, quien al poco tiempo decidió vender la casa e irse a otro lugar para distanciarse de la problemática.

Cuando la familia de Oscar comienza a tomar distancia, llega el momento en que él siente que no quiere causarle más problemas a nadie y él mismo le comunica a Nancy sobre su deseo de "andar por ahí” [divagando en la calle]. Ese fue el comienzo de su vida en la calle.

... me quedo en una esquina por allá por la universidad, al pie de una cafetería donde una señora muy querida, muy chévere, yo le ayudo a hacer el aseo a veces, y ella me da el desayuno o me da algo de almuerzo y ahí... ahí en unos cartones, ahí yo hice como mi rinconcito, ahí me quedo...

Nancy insistía en propiciar encuentros ocasionalmente con Oscar y sus hijos, pero los desplantes sistemáticos, las decepciones y el hecho de que Oscar abandonara su rol de padre llevaron a un completo distanciamiento. Cinco años después Nancy vio a Oscar en el centro de Bogotá, al otro lado de la calle, en total estado de indigencia, con sus greñas y su carrito de reciclaje.

"eso ha sido de las cosas más duras que me ha tocado ver en la vida", dice Nancy. "No sentí ganas de hablar con él, apenas pensé esa es su vida, no hay nada que decirle...."

Efraín, con una pensión de jubilación como sustento y el consumo regular de bazuco, abandonó definitivamente a Rosa y a sus hijos. Argumentaba que él no quería ser responsable de mantener a nadie, lo cual se convirtió en justificación para mantenerse ocasionalmente en la calle y vivir luego permanentemente en ella.

En ese momento comenzó su vida como habitante de calle... "se perdía meses y no sabíamos nada de él". Andaba en las calles de la galería sucio, andrajoso, consumiendo bazuco y pegante. Intentó suicidarse en más de una ocasión. La pensión le alcanzaba solo para dos días y en temporadas dormía en la acera, alquilaba un cuarto por horas o dormía en posadas para indigentes (comenta la familiar).

\section{Rutinas y decisiones de vida}

Oscar vivió en el sector del cartucho ${ }^{16}$ en Bogotá, entre muchos altercados, un día sufrió un atentado que lo llevó herido con dos disparos al hospital. Transcurrieron años y su hermano, quien había sido su compañero de calle, muere. Oscar vivió en la calle alrededor de 20 años, sin embargo, las malas experiencias, dice Nancy, pudieron haber llevado a Oscar a abandonar este estilo de vida e incorporarse a un instituto de rehabilitación. En una reunión fami- 
liar, Oscar le propuso a su esposa vivir juntos nuevamente con sus hijos, con el compromiso de responsabilizarse de algunos gastos, sin embargo, ya rotas las relaciones familiares su hija respondió "... el tiempo de ser familia, como propones, ya pasó”. El hijo de Oscar manifiesta que más adelante quisiera apoyar a su papá para organizarle un taller de ebanistería (carpintería de muebles) en el que él pueda tener un trabajo que le permita solventarse económicamente. Oscar lleva cuatro años en un proceso de rehabilitación.

Jhon continúa su consumo de bazuco y marihuana, trabaja como recolector de café en las fincas de Medellín donde se le facilita albergue para dormir. Mantiene una relación de pareja sin convivencia y su madre concluye:

...actualmente no sé cómo será la clase de vida que Jhon lleva porque prefiero que él esté lejos para yo no martirizarme tanto, yo me martirizo demasiado viéndolo en las condiciones que está él. En ocasiones muy especiales él viene a visitarme, sin embargo, ya es como una piedrita en el zapato, no es porque uno lo quiera señalar con el dedo, pero lo veo con esas ganas de ponerse a consumir que me decepciona cada día más. Hay veces que viene y se queda con nosotros en la casa, otras veces viene saluda y se va, se nota mucho más desorganizado, hablamos muy poco. Cuando él me llama lo escucho que está como ebrio o cuando está como drogado. Me lastima mucho escucharlo de esa manera, así consumido, embriagado. Él siempre me llama en su locura y me dice, quihubo vieja linda o alguna cosa. Yo lo siento dro- gado porque por la forma de hablar yo me doy cuenta como está.

La salud de Efraín tuvo quebrantos y en uno de los episodios terminó dos meses en una unidad de cuidados intensivos por una bronconeumonía severa. Una familiar de Efraín y su hijo menor (quién ya estudia en la universidad) han estado pendientes de la evolución en su salud. Aunque sigue consumiendo alcohol y viviendo en la calle, en una residencia de Manizales, sus relaciones familiares se muestran menos distantes, se toma el tiempo de llamar a la familia, saluda, pero no entra en las casas. Su hijo menor le aconseja "que asegure un poco de estabilidad en su vida".

\section{Discusión}

\section{Las relaciones familiares e interpersonales y la vida en la calle asociada al bazuco}

Metodológicamente hablando, hemos tomado las percepciones y la experiencia colectiva que engloban las voces de familiares de tres casos, frente al uso del bazuco de uno de sus miembros, tratando de conocer desde la práctica el proceso que han vivido frente al tema de la adicción a una droga. En otras palabras, se trata de la interpretación de aquellos que experimentan un miembro de la familia y que afecta de una u otra forma al resto de miembros (padres, hermanos, esposa, esposo, hijos y demás parientes).

En esta forma de abordaje de la adicción, el relato de vida se vuelve un dato que ejemplifica la interacción dialógica que refleja la vida cotidiana de los suje- 
tos consultados, susceptibles de ser interpretados en múltiples contextos similares de manera etno-sociológica (11). Los relatos de vida nos permiten desarrollar conocimiento caracterizado en torno a situaciones específicas de modo, tiempo y lugar, que pueden ser típicas de circunstancias que ejemplifican formas de actuación individual o colectiva. Los relatos desde las experiencias de los testimonios de los miembros de las familias permiten establecer puntos de contraste en diferentes momentos y formas de vivir de quienes relatan el evento.

Lo anterior nos permite orientar las reflexiones en torno al uso de drogas desde la experiencia social, es decir, no como una problemática exclusiva del sujeto que las usa, sino en relación con las personas y colectivas que interactúan y rodean al sujeto.

Las familias y el círculo de amigos o personas cercanas constituyen redes de relaciones o micro-medios de relaciones interpersonales, donde los vínculos afectivos y morales son importantes como generadores de sentido. Como señala Bertaux, "la vida en grupo implica necesariamente 'compromisos' emocionales y morales, más o menos recíprocos de sentimientos (afectos), de responsabilidades específicas y expectativas de sociabilidad" (11). En esta misma perspectiva se interpreta que existe una presión sobre cada uno, él/ella, para desarrollar conductas conforme a las expectativas de los otros miembros. Por lo que no serían comprensibles las acciones de un sujeto que ignora todos los pequeños grupos del cual él o ella hacen parte en tal o cual momento de su existencia ${ }^{17}$.

Así es que el desarrollo de un estilo de vida (6) en torno al consumo de bazuco puede llegar a reconocerse como una adicción de orden cíclica que obedece a un panorama de dependencia, en el cual el sujeto compromete su locus de control interno y externo, se olvida de sí mismo, lo que le genera un abandonarse de lo otro (su contexto) y de los otros (su familia, comunidad, etc.) de manera paulatina. En términos psicoanalíticos, este ciclo de consumo compulsivo se caracteriza por el principio del placer (12), el cual demanda satisfacción en tanto que se plantea la necesidad del sujeto de ir a buscar lo placentero y huir del displacer, en contraposición se subordina el principio de realidad que actúa como un deber ser que se apoya en la realidad externa y en la experiencia personal.

La adicción al bazuco involucra no solo al sujeto sino a todo su contexto familiar. El vínculo afectivo sufre transformaciones, implicando experiencias de tristeza, abatimiento, frustración e impotencia, los cuales pasan a ser explícitos, sin duda, afectando la cotidianidad de la familia (13).

En este sentido, la adicción al bazuco se constituye en un riesgo también para el quiebre de las relaciones sociales, en tanto disminuye la habilidad para sociabilizar con otras personas, entendiendo la sociabilidad como capacidad para

${ }^{17}$ Sus proyectos mismos han sido hablados, dialogados, negociados, con los parientes o personas cercanas. 
mantener relaciones sociales enmarcadas en normas, límites y de lo socialmente aceptado.

\section{La ruptura de los lazos de alteridad con el otro}

El estilo de vida en la calle de un miembro del grupo familiar genera al interior de las familias situaciones molestas, tensionantes y en ocasiones violentas, que afectan la convivencia, la confianza, el respeto, la credibilidad y los vínculos. Las familias que viven experiencias de adicción al bazuco, usualmente cambian sus dinámicas y con el tiempo los familiares comienzan a deteriorar sus sentimientos, actitudes, comprensión y pensamientos hacia la persona adicta. La dinámica de las relaciones, la comunicación y las conductas cambian y se tornan problemáticas como resultado del proceso con el bazuco.

A manera de conclusión, se han recogido diferentes voces (polifonía de voces), que dan sustento a la realidad y a los relatos de vida sobre el fenómeno de la habitabilidad en calle y su relación con el consumo del bazuco. Se ha sintetizado lo narrado organizando la información de manera procesual y resaltado en el análisis los momentos concretos que se relacionan con las lógicas de acción colectivas y subjetivas. En los casos estudiados se caracteriza, en el contexto del ámbito familiar, una conexidad entre el consumo de bazuco y el fenómeno de habitabilidad en calle.

Las trayectorias de vida familiar en torno al consumo del bazuco muestran una experiencia de frustración dolorosa y difícil para todos los miembros del grupo, que en los casos analizados resultan impotentes frente a la magnitud y la complejidad de la problemática. De la misma manera, las trayectorias de vida familiar nos muestran que la dependencia al bazuco es un proceso que puede durar años en el que progresivamente el sujeto consumidor experimenta un deterioro físico y cognitivo que va teniendo un efecto en la relación con su entorno social, al perder las habilidades de interacción. 


\section{Referencias bibliográficas}

1. Castellanos Obregón, JM y Espinosa Herrera, G. Revisión de las tendencias de investigación sobre consumo de sustancias ilegales por los jóvenes. Revista Virajes. 2013;15(2):57-71

2. Henao, S. Representaciones sociales del uso de "drogas" y de las intervenciones respectivas en un contexto local: la Universidad de Antioquia en Medellín, Colombia [tesis de doctorado: impreso]. [España]: Universidad de Granada, España; 2010.

3. Bourdieu, P. Espíritu de familia. 1994. En Neufeld, Neufeld, M.R.; Grinberg, M.; Tiscornia, S. y Wallace, S. Antropología social y política. Hegemonía y poder: el mundo en movimiento. Revista Eudeba. 1998; 57:58.

4. Espinal I; Gimeno A; González F. El enfoque sistémico en los estudios sobre la familia. Revista internacional de sistemas No. 14. 2006 [citado 2017 pg. 13]:114. Disponible en: http://www.uv.es/jugar2/ Enfoque\%20Sistemico.pdf

5. El Espectador. En Colombia hay ocho millones de indigentes [Internet]. 2009 ag. 24 [citado 2017 ag. 13]. Disponible en: https://www.elespectador.com/economia/ articulo157682-colombia-hay-ocho-millones-de-indigentes

6. Guillaume, D; Clua R. Acercamiento socio-antropológico al concepto de estilo de vida. Revista de ciencias sociales Aposta. 2015;66: 87.

7. Moreno C; Espinosa G; Zapata L.Entre el hogar y el asfalto: relatos y experiencia de vida de habitantes en condición de calle. Revista Lasallista de investigación. 2017;14(2).

8. Correa M. Para una nueva comprensión de las características y la atención social de los habitantes de calle. Revista Eleuthera. 2007;1:91-102.

9. Correa-Lagos C. Manifestaciones sociopsicológicas del carácter frente al consumo compulsivo de bazuco. Revista Cultura y Droga. 2017;22(24):119-41.

10. Schnitman, L. Crack droga, adicción y cultura. Colombia: Catálogo científico; 1987.

11. Bertaux, D. Le récit de vie. Paris: Arman Colin Bertaux, 2016. 45 p.

12. Freud, S. Psicología de las masas y análisis del yo. Vol. XVIII. Obras completas. Buenos Aires: Amorrortu editores; 1979. $67 \mathrm{p}$.

13. Pichón, E. Diccionario de psicología social: Teoría del vínculo. Buenos Aires: Nueva Visión; 1980.

14. Samper, P. Drogas: Prohibición y legalización. Bogotá: Debate Sentencia de la Cohorte Constitucional de Colombia C-221-1994; 2013.

15. Revista Semana. Bazuco, el vicio del diablo [Internet].1983 ag. 15 [citado 2017 ag. 13]. Disponible en: www.semana.com/especiales/articulo/ bazuco-el-vicio-del-diablo/3272-3

16. El Tiempo. El bazuco, el gran azote de los habitantes de la calle [Internet]. 2016 dic. 26. [citado 2017 ag. 13]. Disponible en: http://www.eltiempo.com/justicia/cortes/los-efectos-del-basuco-en-los-habitantes-de-calle-37987

17. Moreno C. y Zapata L. Etnografía de prácticas delictivas y consumo de sustancias psicoactivas ilícitas entre jóvenes infractores de la ciudad de Manizales. Revista Virajes. 2013;15(2):15-55. 